\title{
Iron and manganese cycling influence on alkalinity from a redox stratified water column of the Chesapeake Bay
}

\author{
AUBIN THIBAULT DE CHANVALON ${ }^{1}$, GEORGE \\ LUTHER $^{2}$, BRADLEY TEBO ${ }^{3}$, EMILY ESTES ${ }^{2}$, JENNIFER \\ NECKER $^{2}$, JIANZHONG SU ${ }^{2}$ AND WEI-JUN CAI ${ }^{2}$
}

${ }^{1}$ Université de Pau et des Pays de l'Adour, E2S UPPA, CNRS, IPREM

${ }^{2}$ University of Delaware College of Earth, Ocean, and

Environment

${ }^{3}$ Oregon Health \& Science University

Presenting Author: aubin.thibault-de-chanvalon@univ-pau.fr

Suboxic processes are known to strongly modify alkalinity, while oxygen and sulphide are depleted, because the release of $\mathrm{Fe}^{2+}$ and $\mathrm{Mn}^{2+}$ increases the stock of positive ions. However, in low salinity and acidic water, carbonate dissolution can play a similar role due to $\mathrm{Ca}^{2+}$ production. Working with a high vertical resolution pumping system in the Chesapeake Bay during the summers of 2017 and 2018, we analysed iron and manganese speciation, sulphide and nitrite concentration, $\mathrm{pH}$ and DIC in order to identify the controls of total alkalinity variations within the water column. The effect of sea and fresh water mixing is estimated by a two end member model. It appears that the strong dynamic of dissolved metal oxidation must be considered to understand the alkalinity changes as enlightened by the production of abundant manganese oxide above the sulfidic zone. 